\title{
Erratum to: Locked posterior shoulder dislocation: treatment options and clinical outcomes
}

\author{
Benedikt Schliemann • Daniel Muder • \\ Jan Geßmann • Thomas A. Schildhauer • \\ Dominik Seybold
}

Published online: 5 August 2011

(C) Springer-Verlag 2011

\section{Erratum to: Arch Orthop Trauma Surg \\ DOI 10.1007/s00402-011-1310-9}

Owing to an unfortunate error, Fig. 7 displays a copy of a figure published in an article by Gavriilidis et al. ("Chronic locked posterior shoulder dislocation with severe head involvement" Int Orthop 2010 Feb;34(1):79-84. Epub 2009 Mar 20). Although, permission to publish that figure in our article has been obtained, the figure has to be replaced by the following X-rays:

Fig. 7 Hemiarthroplasty for a massive humeral head defect
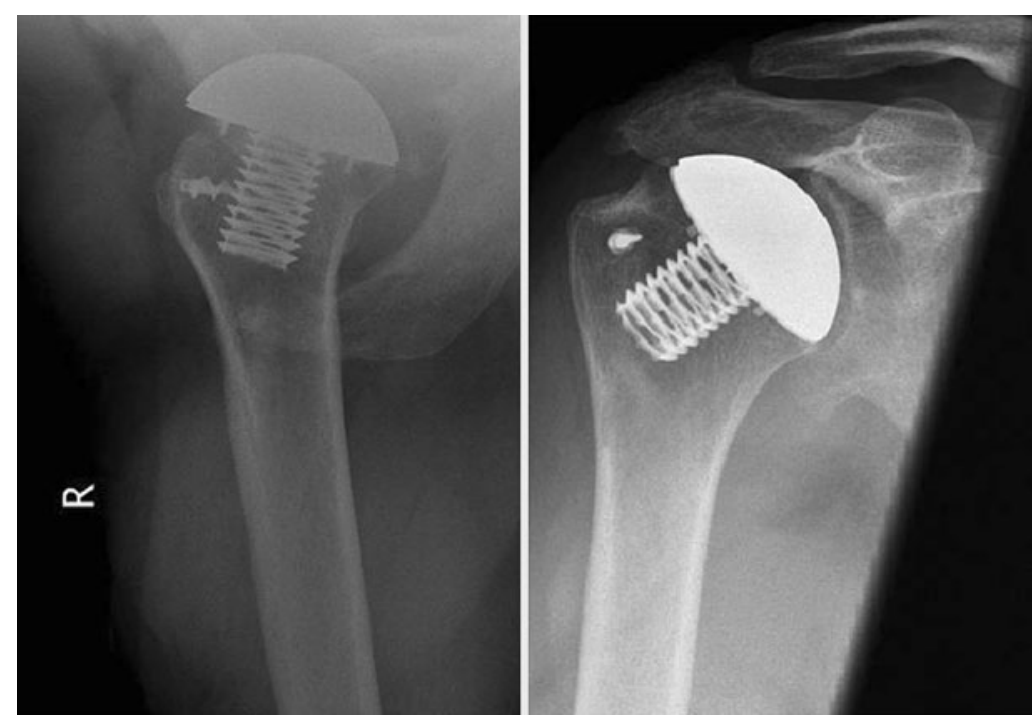

The online version of the original article can be found under doi:10.1007/s00402-011-1310-9.

B. Schliemann

Department of Trauma, Hand and Reconstructive Surgery,

University Hospital Münster, Waldeyerstr. 1,

48149 Münster, Germany

D. Muder · J. Geßmann · T. A. Schildhauer · D. Seybold ( $\square)$

Department of Trauma Surgery, BG-University Hospital

Bergmannsheil Bochum, Bürkle-de-la-Camp-Platz 1,

44789 Bochum, Germany

e-mail: dseybold@mac.com 